\section{LB 009 - Topical treatment with a single occlusive dose of Triptolide (TRP) on actinic keratosis lesions of UV-B-induced mice is highly efficacious and well-tolerated}

\author{
A. Pillon, A. Cousy, P. Cèbe, N. Steward, J-Ch. Blanchet, Ch. Long, A. Grondin, \\ Y. Brunel, B. Gomes \& I. Nguyen*
}

Institut de Recherche Pierre Fabre, 3 av Hubert Curien, 31050 Toulouse cedex, France *thien.nguyen@pierre-fabre.com

\section{Pierre Fabre}

\section{INSTITUT DE RECHERCH}
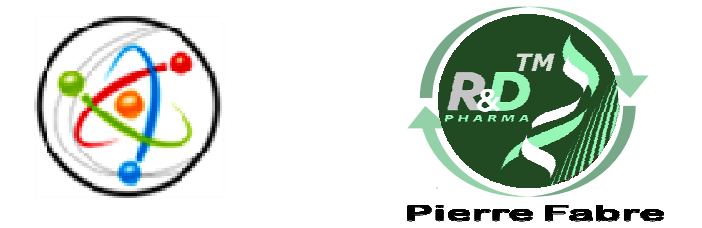

European Society for Dermatology Research ESDR, $47^{\text {th }}$ Annual Meeting September 27-30, 2017 - Salzburg - AUSTRIA

\section{INTRODUCTION}

Actinic keratosis (AK) is a skin disease due to cumulative sun exposure of usually fair-skinned people mostly located on the head, neck, hands and forearms. AK lesions are public health concerns since their presence flags significantly raised risks of progression to skin carcinoma and melanoma. There is a high need for therapeutic improvements in terms of efficacy and tolerance. Tripterygium wilfordii (TW) has been widely used in traditional Chinese medicine for centuries in the treatment of inflammation, autoimmune disease and more recently cancer ${ }^{1}$. Among numerous TW identified compounds, Triptolide (TRP) was shown to be the most potent in term of targeted cytotoxicity. Here we evaluated topical TRP efficacy on UV-B-induced skin lesion in a pre-clinical mouse model.

\section{METHODS}

TRP was purified from TW plant cell culture ${ }^{2}$. Hairless SKH-1 mice were UV-B-exposed every single day for 15 weeks to generate AK lesions. Then animals were topically treated with a single, occlusive dose for $30 \mathrm{~h}$ with either vehicle, or $10 \mu \mathrm{g}$ or $50 \mu \mathrm{g}$ TRP. Twenty days later, treatment efficacy was assessed by skin lesions counting, skin histology and immunohistochemistry ${ }^{3}$.

\section{UV-induced actinic keratosis mouse model}
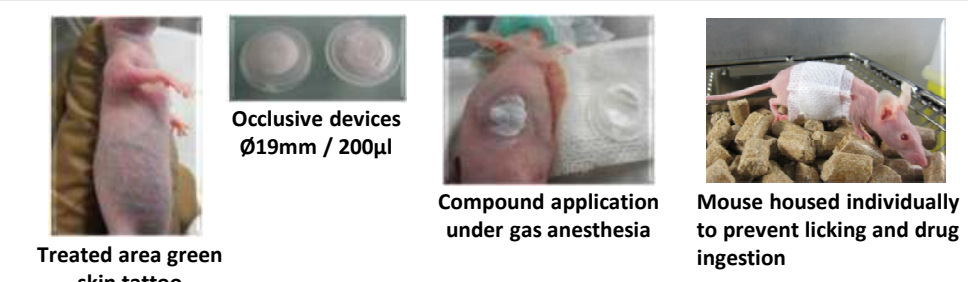

Fig. 1A

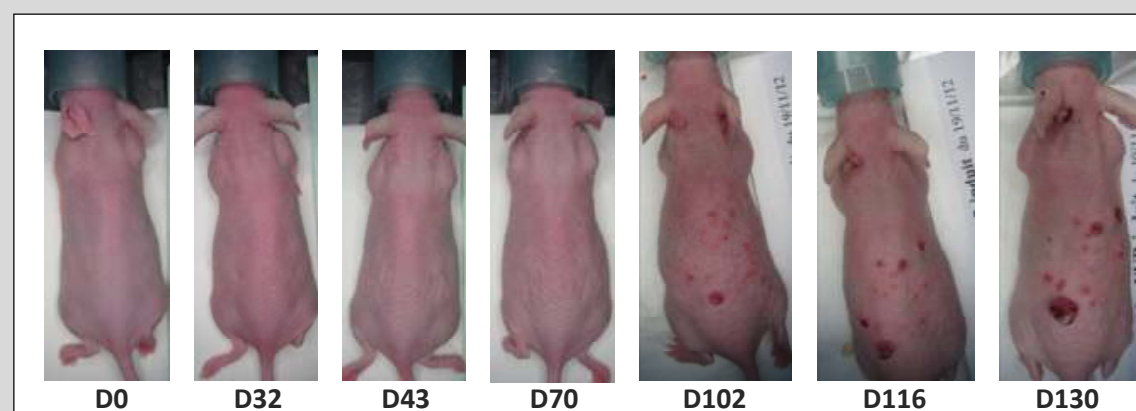

Fig. 1B

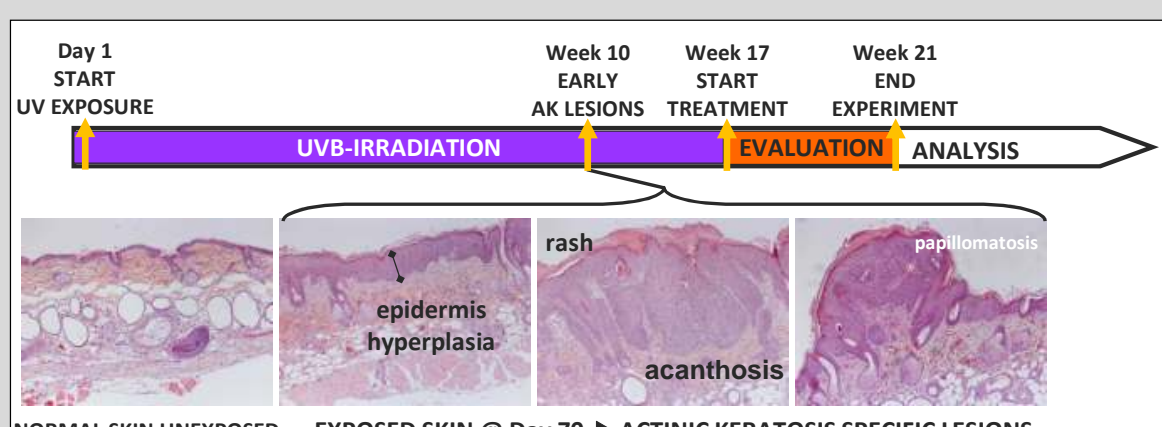

Fig. 1C

Figure 1. 1A) Example of tattooed area and use of the chamber system to perform topical application. 1B) Photographs of UV-B-irradiated mouse skin at indicated days (D) after irradiation initiation (D0). 1C) Study schedule and histopathologic skin evaluation compared to normal skin ${ }^{3}$

\section{Triptolide inhibits UV-induced AK lesions}
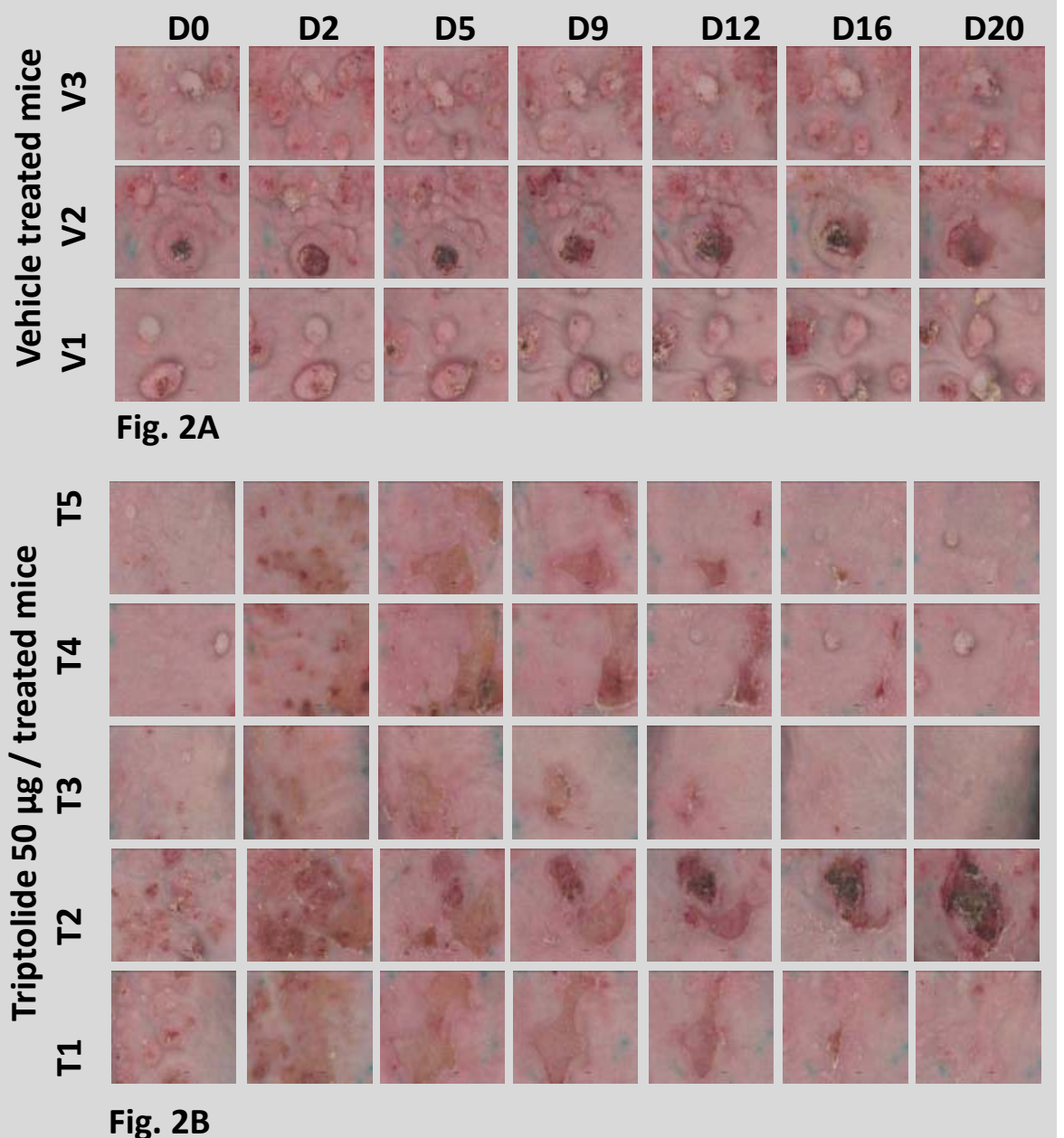

Figure 2. Effect of TRP treatment on UV-B-induced skin lesions captured by Ultra high definition of Digital Dermatoscope (Pixience, Toulouse, France). Skin appearance after either vehicle (2A) or $50 \mu \mathrm{g}$ TRP (2B) topical single and occlusive treatment $(30 \mathrm{~h})$, at indicated days (D) after treatment initiation (D0). Representative pictures are shown.

\section{Skin lesions quantification and TRP efficacy}

\begin{tabular}{|c|c|c|c|c|c|}
\hline $\begin{array}{c}\text { Treatment } \\
\text { groups }\end{array}$ & Mice Id & $\begin{array}{c}\text { Before } \\
\text { treatment }\end{array}$ & $\begin{array}{c}\text { After } \\
\text { treatment }\end{array}$ & $\begin{array}{c}\text { Lesions NB } \\
\text { in/decrease }\end{array}$ & Average \\
\hline & 1 & 8 & 10 & 2 & \\
Vehicle & 2 & 5 & 9 & 4 & +30 \\
treated & 3 & 10 & 10 & 0 & $\mathbf{+ 3 0}$ \\
mice & 4 & 13 & 13 & 0 & \\
& 5 & 4 & 10 & 6 & \\
\hline & 11 & 7 & 5 & -2 & \\
Triptolide & 12 & 6 & 4 & -2 & $\mathbf{- 2 7}$ \\
$\mathbf{1 0} \boldsymbol{\mu g}(30 \mathrm{~h}$ & 13 & 7 & 8 & 1 & \\
occlusive) & 14 & 16 & 9 & -7 & \\
& 15 & 1 & 1 & 0 & \\
\hline & 6 & 7 & 1 & -6 & \\
Triptolide & 7 & 6 & 2 & -4 & $-\mathbf{8 5}$ \\
$\mathbf{5 0 ~ \mu g}(30 \mathrm{~h}$ & 8 & 7 & 0 & -7 & -7 \\
occlusive) & 9 & 9 & 2 & -9 & \\
& 10 & 10 & 1 & -9 & \\
\hline
\end{tabular}

Fig. 3A

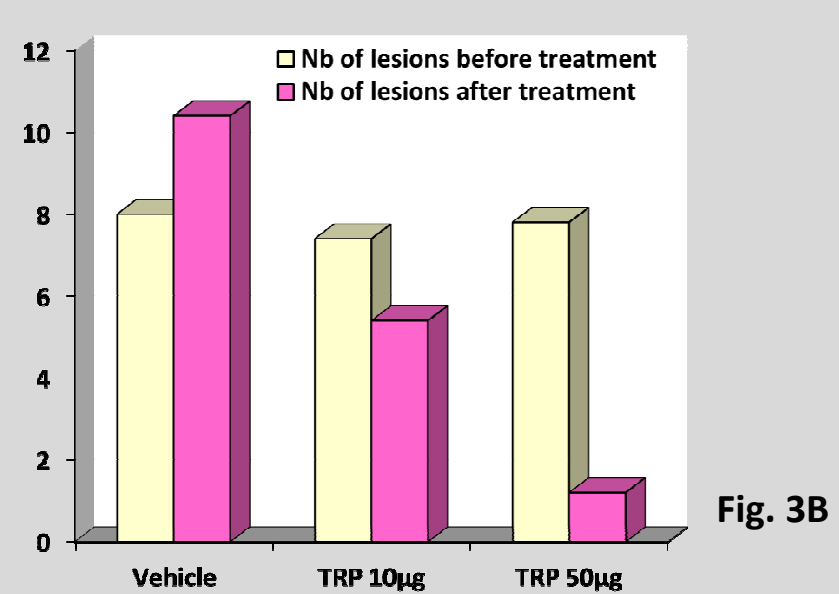

Figure 3. Assessment of the number of skin lesions in control vehicle and $10 \mu \mathrm{g}$ or $50 \mu \mathrm{g}$ TRP treated mice, before (D0) and after treatment (D20). 3A) Skin lesions counting for each individual mouse and average of in/decrease number of lesions. 3B) Bar chart representation showing an increase of lesions in control vehicle treated mice and a significant dose-dependent decrease in TRP treated groups.

\section{Histology and Immunohistochemistry}

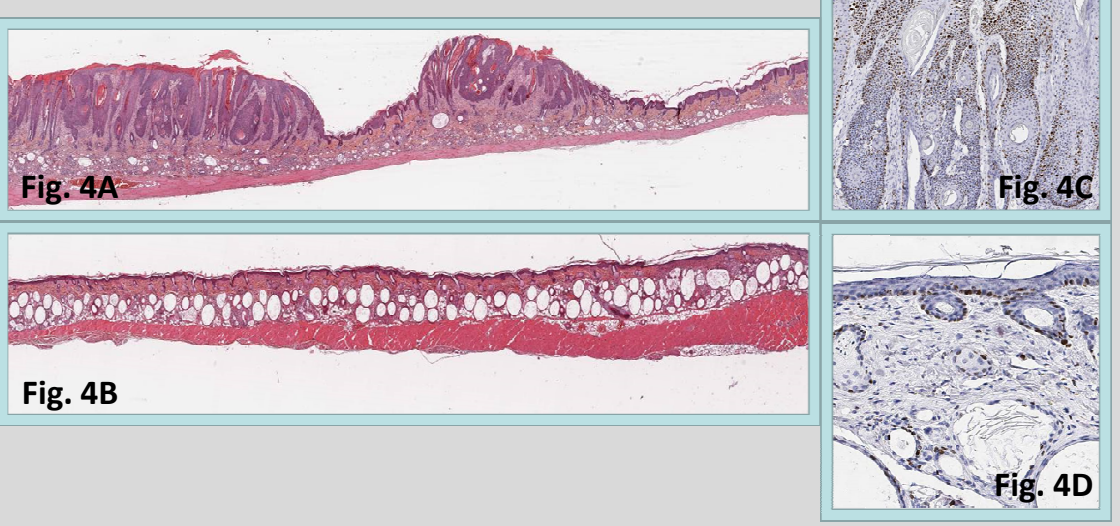

Fig. 4B

Figure 4. Representative histology of UV-B-induced mouse skin topically treated with either control vehicle or $50 \mu \mathrm{g}$ TRP. 4A-4B) Hematoxylin and eosin staining of vehicle and TRP treated skins, respectively. 4C-4D) Ki 67 IHC staining of vehicle and TRP treated skins, respectively.

\section{RESULTS}

The number of AK lesions in animals treated with 10 and $50 \mu \mathrm{g}$ of TRP was decreased by 27 and $85 \%$, respectively. In stark contrast, AK lesions increased by $30 \%$ in vehicle-treated animals. Moreover, TRP efficiency does not appear to be confined to the treatment area but extended to adjacent regions. Furthermore, skin histological analysis confirmed TRP treatment efficacy with normal skin regeneration, thinner epidermis and less proliferative keratinocytes as reflected by a lower number of $\mathrm{Ki} 67$ cells localized in the basal membrane of the epidermis when compared to vehicle-treated skin. No weight loss and minor local inflammation were observed in TRP-treated animals.

\section{CONCLUSIONS}

In this study, we showed that a single dose of TRP was highly efficacious and safe in decreasing the number of AK lesions in a UV-B-exposed SKH-1 mouse model in a dose dependent manner. Therefore, TRP is a potential candidate in treating and preventing human AK lesions. TRP was obtained in minute amount by using classic extraction from TW plant roots. Fortunately, by plant cell culture, TRP could be overproduced by secondary metabolites engineering ${ }^{2}$. Thus, TRP represents a highly added value compound using biotechnology in a economic and sustainable manner.

\section{REFERENCES}

(1) Brinker et al. Phytochemistry. 2007;68(6):732-66

(2) WO 2011054929 Pierre Fabre Medicaments

(3) Pillon et al. PLoS ONE 2017;12(6): e0179991.

\section{ACKNOWLEDGEMENTS}

This study was sponsored by Pierre Fabre Dermatology $R$ \& D. We thank N. Rouziq, S. Davison and J.J. Voisard (Director of Pierre Fabre Dermatology). 